\title{
Militarização das escolas públicas do distrito federal: uma análise sobre a violência ${ }^{1}$
}

\section{Militarization of public schools in the federal district: an analysis of violence Militarización de escuelas públicas en distrito federal: un análisis de la violencia} MARIANA TEIXEIRA DOS SANTOS
https://orcid.org/0000-0002-7420-0529
Fecretaria de Estado de Educação do Distrito Federal
Fepartamento de Educação
Brasília, DF, Brasil
THIAGO DE FARIA E SILVA
https://orcid.org/0000-0001-7205-0021
Instituto Federal de Brasília
Faculdade de História
Núcleo de Ensino de Humanidades e Linguagens
Brasília, DF, Brasil

Resumo: O artigo analisa o Projeto Piloto Escola de Gestão Compartilhada, que alterou quatro escolas públicas para colégios da Polícia Militar do Distrito Federal, no ano de 2019. São objetivos do trabalho: identificar os elementos legitimadores da instauração da gestão compartilhada, investigar se a violência é um fenômeno pertinente na eleição do projeto e detectar os medos da comunidade escolar. A estratégia de pesquisa utilizada foi o estudo de caso de um Colégio da Polícia Militar do Distrito Federal, e incita o debate sobre a violência escolar e a militarização das escolas públicas.

Palavras-chave: Violência. Medo. Disciplina. Militarização escolar.

\begin{abstract}
The article analyzes the Shared Management School Pilot Project, which changed four public schools to Military Police Schools in the Federal District in 2019. The objectives of the work are to identify the elements that legitimize the establishment of Shared Management, to investigate whether violence is a relevant phenomenon in the election of the project and to detect the fears of the school community. The research strategy used was the case study of a Military Police School in the Federal District and incites the debate about school violence and the militarization of public schools.
\end{abstract}

Keywords: Violence. Fear. Discipline. School militarization.

1 Este artigo é síntese de uma pesquisa apresentada ao Curso Especialização em Ensino de Humanidade e Linguagens do Campus Riacho Fundo do Instituto Federal de Brasília, como requisito para obtenção de título de especialista em Ensino de Humanidades e Linguagens. 
Resumen: El artículo analiza el Proyecto Piloto Escuela de Gestión Compartida, que cambió cuatro escuelas públicas a Colegio de Policía Militar en el Distrito Federal en el año 2019. Los objetivos del trabajo son identificar los elementos legitimadores del establecimiento de la Gestión Compartida, investigar si la violencia es un fenómeno relevante en la elección del proyecto y detectar los temores de la comunidad escolar. La estrategia de investigación utilizada fue el estudio de caso de un Colegio de Policía Militar del Distrito Federal y incita al debate sobre la violencia escolar y la militarización de las escuelas públicas.

Palabras clave: Violencia. Miedo. Disciplina. Militarización escolar.

\section{INTRODUÇÃO}

Entender a relação da política educacional de instalação de escolas cívico-militares e a ideia de violência no ambiente escolar motivou a busca pela construção deste trabalho. Dessa forma, o medo de que a escola possa não ser um ambiente seguro tem colocado em questão a estrutura e o funcionamento dessa instituição tão importante no processo de escolarização, de construção do conhecimento e de interação social.

Nossa reflexão busca fornecer elementos para a discussão dessa relação entre educação e segurança pública, principalmente ao procurar entender o medo e as inquietações presentes nas escolas públicas militarizadas do Distrito Federal (DF). O objeto de estudo, problemática que motiva a edificação do trabalho, dedica-se a analisar o Projeto Piloto Escola de Gestão Compartilhada, que preconiza a transformação de quatro escolas públicas em colégios da Polícia Militar do Distrito Federal (PMDF), sendo popularmente conhecido como "militarização das escolas públicas". A proposta inicial que norteia o trabalho é compreender quais fatores legitimam a implementação da gestão compartilhada (GC). Em seguida, buscamos identificar se a violência é um fator relevante na escolha do projeto. Por fim, procuramos investigar quais são os medos da comunidade escolar.

O presente estudo se justifica pela necessidade de construir um conjunto de reflexões e discussões sobre a militarização do ambiente escolar. Ademais, buscamos, principalmente, fomentar o debate sobre as possibilidades de avanços e melhorias educacionais, tendo em vista a necessidade de ações estatais que possam assegurar os direitos dos profissionais da educação e alunos, proporcionando um ambiente de trabalho seguro, saudável e promissor. 


\section{MILITARIZAÇÃO DE ESCOLAS PÚBLICAS: A EXPERIÊNCIA DO DISTRITO FEDERAL}

A GC no DF é uma ação dentro do Programa SOS Segurança, executada no início do ano de 2019, com a mudança de gestão do Poder Executivo do DF na figura do novo governador Ibaneis Rocha. Esta foi regulamentada legalmente pela portaria conjunta no 01 , de 31 de janeiro de 2019. Apesar de a militarização de escolas públicas não ser um fenômeno novo, muitas controvérsias são geradas dentro das teorias educacionais, porém, até o momento, no DF, não havia experiências desse gênero. As administrações dessas escolas não estão descritas em um Plano Nacional de Educação, ficando a cargo de demandas e gestões locais a decisão das prerrogativas de atuação da polícia militar em âmbito estadual e municipal.

Nesses contextos, há o compartilhamento da gestão, pois a composição é dividida em: Gestão Estratégica (PMDF/SEEDF), norteada por portaria complementar; Gestão Disciplinar Cidadã (PMDF), ficando a cargo do comandante da PMDF; e Gestão Pedagógica (SEEDF), norteada pelo diretor da unidade escolar. Sabe-se a Disciplinar Cidadã e a Pedagógica estão situadas no mesmo plano horizontal hierárquico, uma vez que a atuação e as decisões do ambiente escolar não mais ficarão a cargo da Secretaria de Estado de Educação (SEEDF), mas sim de deliberações que envolvam o equilíbrio entre os dois órgãos

As unidades de ensino do DF que estão inseridas no projeto piloto e que passam a ter em sua estrutura a presença da Secretaria de Estado de Segurança Pública são as seguintes: Centro Educacional 03 de Sobradinho; Centro Educacional 308 do Recanto das Emas; Centro Educacional 01 da Estrutural; e Centro Educacional 07 da Ceilândia. Todas elas encontram-se em regiões administrativas distintas, mas compartilham de características semelhantes, ao atenderem critérios estabelecidos no art. $1^{\circ}, \mathbb{S} 1^{\circ}$, da portaria conjunta $n^{\circ} 1 / 2019$, destacando-se a vulnerabilidade social, índices de criminalidade, de desenvolvimento humano e de educação básica.

Para o embasamento teórico de nossa pesquisa, foi realizada a revisão de estudos que abordam a violência no ambiente escolar e a militarização das escolas públicas no período compreendido entre 2010 a 2019. Assim, foram definidos os termos: violência, medo, disciplina e militarização escolar como critérios de busca nos periódicos de distintas áreas de conhecimento das ciências humanas. Outras fontes também foram utilizadas para composição do quadro teórico, tais como a lei federal no 9.394; a Constituição Federal; o decreto n ${ }^{\circ}$ 9.665; a portaria conjunta $n^{\circ} 01$ do Distrito Federal; a lei distrital no 4.751; e a lei federal ${ }^{\circ} 12.086$. 


\section{MÉTODOS E TÉCNICAS APLICADOS NA CONSTRUÇÃO DO ESTUDO}

Quanto à metodologia, o estudo possui aspecto misto, com características qualitativas e quantitativas. Trabalhamos em duas etapas: inicialmente realizamos a revisão bibliográfica e, posteriormente, o trabalho de campo com observação, aplicação de questionários e entrevistas. Assim, a pesquisa apresenta características exploratórias. Apoiando-nos nas prerrogativas objetivadas, optamos pelo estudo de caso de uma das unidades escolares presentes no projeto piloto ${ }^{2}$. A decisão foi realizada devido à necessidade de um recorte espacial para adequação ao tempo disponível de elaboração da pesquisa de campo, que ocorreu em 2019, à viabilidade e à abertura da instituição.

Apesar de não ser constituído como um trabalho etnográfico, alguns elementos se aproximam desse método. O texto "Cada caso não é um caso", da antropóloga Claudia Fonseca (1999), demonstra que as ditas particularidades percebidas como casos específicos em realidades construídas socialmente podem não ser apenas "um caso", mas uma conjuntura particular estudada sob a ótica da etnografia, que pode alcançar conclusões de níveis macroestruturais. Apesar de as informações estarem vinculadas a uma escola, observa-se a possibilidade de expansão da interpretação para outras realidades que compartilham dos mesmos desafios educacionais, situados em um processo histórico-cultural semelhante.

A observação teve como objetivo presenciar a disposição e a administração da escola, tendo em vista a segmentação entre gestão disciplinar e gestão pedagógica. Formulamos um questionário que oportunizou coletar dados quantitativos e qualitativos acerca dos questionamentos levantados, estruturados com questões objetivas e subjetivas; em seguida, utilizamos o Google Formulário para tabulação dos dados. A aplicação foi realizada por segmentos em dias distintos e houve instrução acerca da voluntariedade e anonimato dos dados informados. Os questionários foram direcionados aos professores, agentes da PMDF, responsáveis pelos estudantes e aos alunos. As indagações objetivaram traçar um perfil dos pesquisados, explorar a percepção sobre as mudanças na escola e identificar a visão sobre violência escolar. $\mathrm{O}$ instrumento era composto de 23 perguntas para os alunos; 16 para os responsáveis; 25 para os professores; e 22 para os policiais.

O universo amostral foi selecionado de acordo com a disponibilidade e aceitação em participar da pesquisa, porém, para os alunos, foi realizado um recorte de série, ao se entender que a temática requisitava um olhar mais 
crítico sobre a própria situação escolar, além do fator idade como requisito para participação de decisões em assembleias promovidas pelo Conselho Escolar. Por isso, o questionário foi aplicado em todas as turmas do $9^{\circ}$ ano do ensino fundamental.

A aplicação iniciou-se com o corpo discente. Do total de 894 alunos, foram coletados 149 questionários (aproximadamente 16\%). Esses estudantes levaram para casa outro questionário direcionado para os responsáveis, recolhidos no dia seguinte, o que totalizou 39 instrumentos. Não foi possível realizar uma porcentagem desse segmento devido à falta de dados do total representativo da amostra. Dos 36 professores que compõem o quadro, 12 responderam à pesquisa (perto de 33\%). Os agentes atuantes na instituição totalizam um universo de 20 policiais, e 9 responderam ao questionário (45\%).

Foram realizadas três entrevistas semiestruturadas com uma professora, um policial e uma representante do Sindicato dos Professores do Distrito Federal (SINPRO-DF), totalizando cerca de 70 minutos de gravação, transcritas e correlacionadas ao quadro teórico de apoio. As entrevistas se justificam devido à necessidade de um aprofundamento sobre assuntos que não foram contemplados na aplicação das demais ferramentas.

Apesar das dificuldades encontradas, inerentes a qualquer pesquisa de campo, a associação entre os questionários, as entrevistas e a observação permitiram a reflexão sobre questões importantes e podem fornecerem resultados instigantes para essa experiência, ainda muito recente, de militarização das escolas públicas do Distrito Federal.

\section{O MEDO DA VIOLÊNCIA: REFLEXÕES SOBRE O IMPACTO NO AMBIENTE ESCOLAR}

A violência nos centros urbanos demonstrou crescimento, apresentandose como uma das maiores preocupações da sociedade brasileira. De acordo com o "Atlas da violência 2019" (IPEA, 2019) foram registrados 65.602 homicídios no Brasil em 2017, uma média de 31,6 mortes a cada 100 mil habitantes, constituindose como o quadro de maior índice já registrado na história do país. Em oposição, o DF mostra outra realidade: "foi a segunda unidade federativa com maior redução na taxa de homicídio em 2017, fato que vem ocorrendo desde 2012, período em que a queda foi 44,3\%.” (IPEA, 2019, p. 20).

Ocorre que, independentemente de classe social ou de variação dos índices de violência, o sentimento de medo e insegurança está permeado em distintos grupos, como se observa nos discursos dos indivíduos em diversos meios de comunicação e manifestações da opinião pública. Nesse sentido, 
para Caldeira (2000, p. 27), o termo "fala do crime - ou seja, todos os tipos de conversas, comentários, narrativas, piadas, debates e brincadeiras que têm o crime e o medo como tema - é contagiante" e possibilita reforçar a sensação de estar em constante perigo, o que retroalimenta o medo, o combate e a ampliação da violência.

É o que revela a pesquisa "Percepções da crise", de 2017, realizada pela Fundação Getúlio Vargas (FGV), que situa o Brasil como o $2^{\circ}$ lugar na lista de medo da violência, descrença no sistema político e falta de confiança estatal. A escola, como uma instituição social, não foge à regra dos acontecimentos sociais, em que a ideia da presença da violência gera o medo da exposição a esse fenômeno. Com o surgimento de novas demandas, a necessidade de reinvenção dos espaços passa a ser um anseio da comunidade escolar.

O Centro Educacional, campo da pesquisa, incorporou o nome Colégio da Polícia Militar do Distrito Federal (CPMDF), tornando-se uma escola militarizada a partir de 2019. Com base na Lei de Gestão Democrática, as escolas que demonstraram e demonstram interesse na aplicação da GC precisam aprovar, em assembleia, através de votação coletiva e democrática, a mudança. Com participação de toda a comunidade escolar, 50\% dos votos são dos pais, responsáveis e estudantes e $50 \%$ dos servidores da carreira de assistência e professores. Ao final, são exigidos mais de $50 \%$ dos votos para que o resultado seja adotado.

Os critérios técnicos informados para escolha da escola a ser militarizada, de acordo com o Projeto Pedagógico (2019), foram os seguintes: baixo Índice de Desenvolvimento Humano (IDH); baixo Índice de Desenvolvimento da Educação Básica (Ideb); altos índices de violência e indisciplina; capacidade estrutural de comportar ensino fundamental do $6^{\circ}$ ao $9^{\circ}$ ano (EF II) e ensino médio (EM).

Considerando as características que permeiam o CPMDF, para análise dos dados coletados, foi realizado um comparativo entre as respostas dos distintos segmentos, referente aos questionamentos: avaliação sobre as principais mudanças realizadas na escola com a implementação da GC; motivos para a implementação da GC; sentimento sobre a presença dos agentes na unidade escolar; percepção acerca do que é a GC; tipos de violência que afirmam ter mais medo dentro do ambiente escolar e seu entorno; incidência do fenômeno violência dentro da escola. As entrevistas foram revisitadas para a contribuição e complementação dos dados explanados. 
Concernente à primeira indagação de ordem avaliativa quanto às possíveis mudanças com a implementação da GC, entre as ponderações dominantes, 36,5\% dos alunos e 33,3\% dos professores julgam como razoáveis; $41 \%$ dos responsáveis veem como excelentes e 55,6\% dos policiais indicam ser muito boas. Além da resposta objetiva, também era possível justificá-la.

Alguns alunos avaliam como positivo o fato de ter mais regras, além da ideia de maior segurança e disciplina na escola, porém, outros não estão satisfeitos com normas que, para eles, não fazem sentido, como a padronização dos cabelos. Os pais consideram como efetivas as mudanças, principalmente no que tange à segurança e à diminuição da criminalidade dentro da escola. Há uma divisão de opiniões entre os docentes. Para os policiais, houve avanço em relação aos quesitos disciplina e segurança. Alguns termos foram recorrentes na questão dissertativa, que requisitava justificativa, como: segurança, disciplina, violência e comportamento.

Carvalho (1996) traz contribuições ao pensar sobre disciplina ou indisciplina no contexto escolar. As definições desses termos estão relacionadas aos valores construídos culturalmente e se apresentam de forma distinta nas instituições. O autor conceitua disciplina como "o conjunto das prescrições ou regras destinadas a manter a boa ordem” (p. 130). Esse pressuposto de disciplina se assemelha ao do contexto militar e monástico, porém, ressaltamos ser distinta a sua utilização no contexto escolar.

A diferenciação não pressupõe que o contexto escolar não seja organizado por regras, mas a alusão de que, para os militares e os eclesiásticos, a disciplina incita um controle de comportamento centrado em objetivos únicos: a força capaz de enfrentar o conflito e a inspiração de valores religiosos. Para a escola, a disciplina é menos fundamentada em uma ordem rígida de procedimentos comportamentais e mais arrolada na aprendizagem de conhecimento. Carvalho (1996) ressalta que o vínculo entre a disciplina, como regras de comportamento e a área do conhecimento, gera problemas para o entendimento da disciplina específica ao ambiente escolar.

Ademais, segundo Foucault (2013), o objetivo da disciplina como um instrumento de poder é a docilização dos corpos, fabricando as necessidades exigidas do campo social, econômico e político, de maneira que não haja insubordinação às ações estatais. Com a reorganização escolar para atender às novas demandas e preceitos, organizou-se "uma nova economia do tempo de aprendizagem. Fez funcionar o espaço escolar como uma máquina de aprender, mas também de vigiar, de hierarquizar, de recompensar" (p. 122). Os espaços de escolarização vão aplicando a disciplina e o controle minuciosamente e 
reproduzem tecnologias de poder no exercício disciplinar sem critérios de função social, passando a seguir uma mesma ordem: a de estabelecer a obediência como conduta de regulamento.

Ao criar regras e transmitir uma disciplina, a escola não deve impedir o educando de criar. Na verdade, deve possibilitar a criação, pois as regras aplicadas ao ambiente escolar não são unicamente regulamentadoras, elas também podem ser constitutivas de novas práticas. A disciplina na escola não está (ou não deveria estar) comprometida com a padronização de comportamentos, mas na apropriação de práticas que proporcionem aprendizagem, atividade inerente às instituições escolares. As entrevistas remetem a algumas múltiplas reflexões sobre o "papel da escola" e a "reinvenção do espaço escolar":

E aí, assim, a polícia vai dar jeito naquilo que a escola, junto com os professores, não deram, mas tudo bem! Nós não damos conta de cuidar da higiene pessoal dos meninos, de ensiná-los que eles precisam falar "bom dia", "boa tarde", agradecer, solicitar alguma coisa "por gentileza", quando for necessário, porque isso não é o nosso papel, isso precisa estar muito claro, mas a sociedade brasileira não entende assim. Tanto que esse comportamento de que alguém vai cuidar, eu vou delegar para alguém fazer, porque dá muito trabalho criar filho, e dá mesmo. Eu faço isso para quem? Eu faço isso para a escola, eu faço isso para a polícia e tanto que isso é comum no... quanto se você colocar nessa comunidade de Águas Claras ou da Asa Sul, a perspectiva é a mesma: "Ah não, os militares vão cuidar melhor, porque eles vão disciplinar [...]". (Representante sindical do SINPRO).

Porque assim, para nós conseguirmos ter uma educação de qualidade na escola, os alunos precisam vir educados de casa e muitos deles não têm, assim, sabe, os pais na maioria acham que escola é onde o filho vai ser educado. E não é só agora no ensino fundamental, é dos pequenininhos mesmo, eu vejo uma transferência de responsabilidade. (Professora do CPMDF).

Eu acho que a situação chegou a um ponto que a comunidade clamou por uma nova opção. Uma nova opção que pudesse oferecer uma resposta, uma tentativa. E tendo como base as escolas militares tradicionais, começou-se a se pensar se seria uma opção, é aumentar o leque de opções. As formas de estudo, de... A forma de lidar com o ambiente escolar. (Policial do CPMDF).

Quando analisamos os discursos da comunidade escolar, a disciplina tão aclamada não é a que possibilita adquirir habilidades e conhecimentos, mas a que objetiva apenas a padronização dos comportamentos. Ela é comum para instituições militares, de acordo com Carvalho (1996), para a polícia assegurar o seu objetivo fim. Por outro lado, a escola possui outro desígnio, necessitando de comportamentos diversos, pois o processo de ensino e aprendizagem é uma variável e exige metodologias diferenciadas, que são possibilitadas por outra forma de disciplina, capaz de construir novas práticas, o que nos instiga a repensar o papel da escola como disciplinadora. 
Aqui ressaltamos a visão de Foucault (2007) sobre a legitimidade de quem fala. Certamente, os professores e a administração escolar sempre trouxeram o cumprimento de regras como uma prerrogativa necessária em um espaço comunitário como a escola. Porém, quando o mesmo discurso é proferido por quem, no momento histórico, detém uma sobreposição hierárquica e a instrumentalização da punição, este passa a reverberar com maior força de verdade.

A legitimidade que é designada advém da cultura, pois é a cultura de determinada sociedade, assim como seu sistema simbólico, que vai configurar o sistema discursivo e as práticas aceitas e reprováveis. A cultura valida quem fala na prática intelectual, reproduzindo, através do discurso, poder e desejo. Logo, o discurso exerce um poder e é, em si, um objeto e não apenas reflexo de uma realidade, pois tem a potencialidade de criar uma realidade própria através da palavra. Portanto, a força da fala é um domínio de poder. Nas entrevistas e respostas ao questionário, ficam evidentes os diferentes pesos que os discursos possuem:

Olha, eu penso que existe um movimento muito forte na sociedade brasileira, o qual aquela comunidade está inserida, que é essa supervalorização ao sistema militar. (Representante sindical do SINPRO).

Eu falo muito isso aqui, um dos segredos é a repetição, repetir. Todos os dias tem que falar. Reunir os alunos no começo do turno e: "Tem que ser assim, tem que ser assim, tem que ser assim”. Falar todos os dias. Organizar, organização. O aluno tem que saber que dentro da escola tem organização, tem regras a serem cumpridas, não é... Ele não pode fazer o que ele... "Eu não quero assistir aula", aí, não assiste não. Ele tem que saber que é regra, tem que cumprir [...]. Você dá um comando ali que para muitos acham que: "Para que isso?" Formatura, eles saem em fila direto para sala de aula, é dali para a sala de aula, não tem que ficar perambulando pela escola. "Vou ao banheiro"? "Não! Vai ao banheiro depois, agora não, vai sair daqui e vai para a sala de aula". Então, não tem que ter, dar muita margem para o aluno achar que ele faz o que quer na escola, entendeu? Eu acredito nisso. E a gente fala que isso é em qualquer lugar. (Policial do CPMDF).

Mas no início, assim... Porque têm regras e, às vezes, eles não estão acostumados com regras [...] O que acontece? A escola que eu estudei na época... Por muitos anos, o diretor, ele era um diretor que ele teve uma formação militar, então, a minha escola, ela era muito parecida com esse padrão aqui: é obrigatório usar o uniforme; você precisa vir de calça jeans; de tênis, na época era branco ou preto e a blusa do uniforme; o short tem que ser beirando o joelho e só na hora da educação física. Muitas coisas assim. Como questão de disciplina, minha escola foi ótima e é bem parecida com agora. (Professora do CPMDF).

Melhorou a disciplina, respeito, tolerância de alguns alunos, mais aproximação com familiares e mais segurança nas escolas. (Responsável do CPMDF). 
Apesar da ideia de um ambiente mais seguro e disciplinado, não podemos ignorar a insatisfação de muitos alunos, presentes nas seguintes respostas³:

Muitas coisas são desnecessárias, não é um ambiente do qual eu me sinta bem, pois a minha forma de ser, de andar com os cabelos soltos, a minha pessoa em si foi alterada. (Estudante do CPMDF).

Foi boa em algumas ocasiões, pois os alunos ficaram mais respeitosos. Porém, vários alunos não se sentem confortáveis, vão para a escola estudar e acabam voltando oprimidos por algumas situações. (Estudante do CPMDF).

A escola melhorou bastante, porém não temos voz para nada. (Estudante do CPMDF).

Tem mais coisas que eu e outras pessoas não gostam, mas eu sei que só porque eu não gosto não vai mudar. (Estudante do CPMDF).

Os apontamentos relatados incitam a temática de homogeneização do espaço escolar em oposição à observação da escola como um espaço sociocultural, abordada por Dayrelle (1966). Para essa análise, consideramos elementos culturais e todo o dinamismo presente nas relações complexas de interação social. Assim, são construídos papéis em uma instituição socializadora voltada para públicos diversos. A atuação escolar se constitui, então, como um espaço social único, com dupla dimensão, devido à existência de uma ação recíproca e heterogênea entre o sujeito e a instituição.

Para Dayrelle (1966), os indivíduos não são apenas receptores dos ditames vindos da estrutura, mas sim de uma relação cotidiana e de contínua edificação. A escola surge como uma instituição que possui uma série de regras e uma organização oficializada, em contrapartida aos indivíduos que carregam um arcabouço cultural diverso. A realidade escolar é a mediação entre esses dois segmentos, consequência da reciprocidade entre sujeito e instituição, possibilitando a reinvenção do processo educativo com a repetição do velho e a potencialidade de composição do novo.

A homogeneização dos alunos gera uma desarticulação entre conhecimento escolar e a realidade social, reduzindo os sujeitos a uma categoria única de "aluno". Como afirma Dayrelle (1966), as particularidades precisam ser trabalhadas como uma realidade para que não sejam utilizadas como instrumentos que possam segregar os alunos e influenciar negativamente o processo de ensinoaprendizagem.

Os trechos transcritos dos alunos e responsáveis foram coletados pelos questionários e não por entrevista. Foi utilizada a escrita original. 
Quando observamos nos discursos a falta de adequação e adaptação às novas regras, é importante refletir se estas estão sendo impostas para melhoria do espaço e não como forma de padronização para facilitar a aplicação de uma metodologia única que não atinge a todos, o que pode gerar consequências diversas das almejadas. Apesar da consciência da dificuldade de muitos habituarem-se a padrões, a escola pública deve ser representativa da sociedade, independente do projeto pedagógico e disciplinar.

Dando continuidade aos resultados de nossa análise, passamos ao questionamento: "Entre os motivos abaixo, para você, o que motiva a implementação da gestão compartilhada"? Era possível assinalar múltiplas categorias, como: "Redução dos índices de violência na escola"; "Melhora do comportamento disciplinar"; "Melhora do rendimento escolar"; e "O medo que a escola não seja um ambiente seguro". Os resultados predominantes foram: $50 \%$ dos alunos, $51,3 \%$ dos responsáveis e $81,8 \%$ dos professores acreditam ter sido a busca pela redução dos índices de violência na escola o motivo para implementação da GC. Porém, entre os agentes, $77,8 \%$ defende que foi a melhora do rendimento escolar, resposta que se contrapõe à função da PM enquanto um órgão de segurança pública incumbido de realizar policiamento ostensivo e resguardar a ordem pública do DF.

Podemos, assim, responder algumas inquietudes iniciais. Quanto à primeira problemática do estudo, podemos identificar que o principal fator que mobilizou a comunidade escolar a adotar a GC foi o medo da violência. Para o trabalho em questão, o medo fundamenta-se como um fenômeno extremamente relevante que subsidiará apoio a políticas educacionais interventivas através do uso da coerção no ambiente escolar. Em nome do combate à violência, a presença da violência na escola passa a ser exercida pela força policial, que detém o monopólio da violência legítima, de forma análoga à concepção desenvolvida por Weber (1996).

Para Bourdieu (1998), o propósito de imposição e de legitimação de uma classe sobre a outra, definido como uma forma de "violência simbólica", é a operação desse conceito enquanto instrumento. Dessa forma, o sociólogo afirma que as produções simbólicas são instrumentos de dominação.

A implicação prática do poder simbólico pode ser vista nas distintas instituições sociais através da violência simbólica, definida como "uma violência que se exerce com a cumplicidade tácita dos que a sofrem e também, com frequência, dos que a exercem, na medida em que uns e outros são inconscientes de exercê-la ou de sofrê-la." (BOURDIEU, 1998, p. 22). Utilizada como mecanismo 
legitimador de certas práticas culturais engendradas pela classe dominante, os dominados passam a reproduzir e legitimar tal ordem pela crença de única realidade possível.

A escola, assumindo seu papel como espaço de escolarização, constituise como um meio eficaz de reprodução legítima das estruturas. Para Bourdieu (1998), a escola norteia seu funcionamento pedagógico em prol da manutenção da classe mais influente, gerando entraves para uma prática agregadora que considere a subjetividade dos distintos estudantes. O que acreditamos é que esse espaço deveria ser plural.

Para a teoria de Foucault (2013), a ideia da vigilância constante pode ser considerada uma tecnologia de poder, pois o sentimento de segurança é construído no receio da possível penalidade a ser aplicada, fabricando corpos dóceis em virtude do medo de ser alvo da violência externa à escola. Isso possibilita a geração do medo interno, possivelmente disfarçado de bom comportamento e conduta disciplinada. Assim, foi criado o sentimento de segurança nos sujeitos, como pode ser observado nos dados concernentes à pergunta referente ao sentimento sobre a presença dos agentes na unidade escolar. As categorias eram: "Continuo me sentindo do mesmo jeito"; "Já me sentia seguro"; "Passei a me sentir mais seguro"; e "Passei a me sentir inseguro".

A categoria "Passei a me sentir mais seguro" com a presença dos militares teve um índice maior de respostas em todos os grupos. Embora a comunidade aponte se sentir mais segura com a presença dos agentes no ambiente escolar, existe um movimento de crença em outras formas de combater a violência quando analisamos a pergunta: "A Gestão Compartilhada para você é?", visto que a resposta com maior listagem foi "Uma forma de combater a violência nas escolas públicas do DF”. De forma mais elucidativa, os índices de resposta estão representados no quadro abaixo:

\section{Quadro 1 - Percepção dos participantes da pesquisa sobre o que é a Gestão Compartilhada}

\begin{tabular}{|c|c|c|c|c|}
\hline \multirow{2}{*}{ Categorias } & \multicolumn{4}{|c|}{ Participantes da Pesquisa } \\
\cline { 2 - 5 } & Estudantes & Responsáveis & Docentes & Policiais \\
\hline $\begin{array}{c}\text { Uma forma de combater a violência nas } \\
\text { escolas públicas do DF }\end{array}$ & $73 \%$ & $56,4 \%$ & $75 \%$ & $87,5 \%$ \\
\hline $\begin{array}{c}\text { Não melhora a violência nas escolas } \\
\text { públicas do DF }\end{array}$ & $4,9 \%$ & - & $8,3 \%$ & - \\
\hline $\begin{array}{c}\text { A melhor forma de combater a violência } \\
\text { das escolas públicas do DF }\end{array}$ & $22,1 \%$ & $43,6 \%$ & $16,7 \%$ & $12,5 \%$ \\
\hline
\end{tabular}

Fonte: A autora. 
Os dados explicitados acima geram a interpretação de que, apesar de os participantes afirmarem se sentir mais seguros com a presença dos policiais, também acreditam que outras possibilidades poderiam ser mais efetivas.

Uma das principais críticas que a gestão escolar faz é a necessidade de se pensar sobre que outras medidas de segurança escolar estão sendo implementadas, já que existem outras instituições que não estão sendo contempladas com qualquer ação voltada à segurança da comunidade escolar.

Adiante, quando interpelados sobre os tipos de violência que geram o maior medo dentro do ambiente escolar e seu entorno, as múltiplas categorias eram: "agressões físicas"; "ameaças"; "bullying"; "agressões verbais"; "assédio sexual"; "furtos e roubos"; "drogas". A opção "Outros" permitia que o respondente discorresse sobre o que não havia sido contemplado.

Ficou registrado que, entre os grupos, as categorias recorrentes são as denominadas "violência dura" - termo analisado por Abramovay (2015, p. 14) como "atos e episódios que podem resultar em danos irreparáveis aos indivíduos e, por isso, exigem a intervenção estatal.” Para a autora, esse tipo de violência representa a ineficiência do sistema de resolução de conflitos e desigualdades. Os exemplos de materialidade da violência dura, apresentados por ela, são os seguintes: ameaça tipificada no Código Penal Brasileiro, agressão física, assédio e violência sexual, furto, e presença e uso de armas. A autora ressalta a necessidade de uma reflexão acerca da violência tecida pelas problemáticas próprias da organização escolar.

Dentro do ambiente escolar e entorno, os maiores medos dos alunos são: furtos e roubos (68,7\%), agressões físicas (60,3\%) e ameaças (51,9\%). Dos responsáveis são: drogas e agressões físicas $(89,7 \%)$ e assédio sexual $(74,4 \%)$ - talvez essa última tenha relação com a grande quantidade de mulheres que participaram no grupo dos responsáveis. Dos professores são: ameaças $(72,7 \%)$ e agressões físicas e furtos e roubos (ambos com 63,6\%). Dos policiais: três opções tiveram a mesma quantidade de respostas (75\%): agressões físicas, bullying e drogas. Algumas falas das entrevistas colaboram na percepção de como a manifestação do medo é idealizada e como ela se exterioriza na prática: 
A gente sempre, como pai, a gente sempre tem mais medo das questões, dos crimes mais violentos né? Como agressões, lesão corporal, a questão das drogas, os pais têm muito medo, questão de ameaça assusta muito o pai. Então, graças a Deus, aqui a gente praticamente reduziu a zero a incidência. No começo, a gente teve; alunos foram conduzidos para Delegacia da Criança e do Adolescente (DCA) por causa de ameaça, por causa de briga. Hoje, já faz um tempinho que a gente não precisa; o que acontece, a gente tá conseguindo resolver com os pais, porque são coisas mais brandas, bem tranquilas, porque são coisas do ambiente escolar. (Policial do CPMDF).

E a outra influência que tem a ver com imaginário, que a mídia é a grande responsável por propagar esse sistema do medo, que a gente vive em uma cultura de falta de segurança, que está todo mundo se matando, que a gente vive em uma barbárie, a ponto das mães e dos pais acharem que realmente os filhos são propensos, quase que $100 \%$, de sofrerem violência dentro da escola. Quem vai evitar são os policiais. (Representante sindical do SINPRO).

Falar dessa escola é difícil, mas falar de escolas no geral... Sei lá, até o medo de você chamar a atenção de um menino e uma cadeira voar, qualquer coisa assim, sabe? Porque eles, algumas vezes, não têm limites. Uma escola que eu trabalhei, eu colocava minha mesa perto da porta de saída, porque qualquer coisa eu já saio correndo, justamente por isso, questão de conflito mesmo de eles não saberem lidar com você chamar a atenção, fazer uma reclamação, porque nós vemos tantos casos entre os colegas, mas aqui eu não tenho medo não. (Professora do CPMDF).

As próximas perguntas de cunho subjetivo tentam constatar se esses sujeitos já presenciaram ou não algum tipo de violência, tanto anteriores a GC como posteriores. Para a pergunta: "Você já presenciou algum tipo de violência na escola antes da Gestão Compartilhada?", das 123 respostas dos alunos, 96 afirmam nunca ter presenciado ou sofrido esse fenômeno e 27 já presenciaram ou foram vítimas de algum caso. Uma resposta colabora bastante com o medo da ideia de reprodução da violência: "Não, porém tenho medo de sofrer".

Das 39 respostas dos pais, 31 afirmam que os filhos nunca sofreram algum tipo de violência na escola e 8 indicam já ter passado por alguma experiência interligada a esse caso. Dos professores participantes, todos responderam a essa pergunta, e 7 nunca sofreram ou presenciaram, 4 já experienciaram e 1 afirmou não ser capaz de responder. Também foi alcançado o total da amostra dos policiais para essa pergunta e apenas 1 afirmou nunca ter presenciado casos de violência na escola. 
Para a questão: "Você já presenciou algum tipo de violência na escola depois da Gestão Compartilhada?", 118 alunos responderam e destes, 108 disseram "não" e 10, "sim". Dos responsáveis, 38 responderam, sendo 36 negativas e 1 afirmativa. Das 11 devolutivas dos professores, 8 alegaram que "não" e 3 que "sim". Das 9 respostas dos policiais, 5 expressaram "não" e 4, "sim".

Duas respostas subjetivas acerca da pergunta acima requerem ser consideradas: "Não, pois os militares evitam bastante, com punição e opressão" (aluno); "Não, graças a Deus e ao trabalho da polícia, espero que continue assim" (responsável). Essas afirmações colaboram com a ideia de Christian Dunker (2015) acerca da denominação de mal-estar da sociedade contemporânea brasileira que, para o psicanalista, é realizada na idealização da violência. Essa ideia gera ações que, muitas vezes, invertem os meios para que determinadas finalidades sejam alcançadas. Ao se buscar a promoção da segurança, mais insegurança pode ser gerada. As duas falas apresentadas invertem a relação e adotam a militarização como resposta ao medo de algo que, de fato, não aconteceu.

Apesar do medo que possuem, a maior parte dos sujeitos nunca sofreu diretamente a "violência subjetiva", teorizada por Zizek (2014). O autor reforça a importância e os riscos de enfatizar apenas a denominada violência subjetiva, que é de fácil visibilidade, pois abala a ordem tida como normatizada (manifestada pela violência física) praticada pelo Estado e atores sociais. Em contraposição a isso, há a "violência objetiva", com características sistêmica e simbólica, estruturada na ordem social.

No discurso dos participantes da pesquisa, há uma centralidade e uma urgência em combater a violência, acabando por velar o pensar sobre outras formas de combater a violência sem reproduzi-la. De acordo com Zizek (2014), a evidência que é dada para as violências, sejam elas subjetivas ou objetivas, vai influenciar no combate e na contraposição, ainda que de maneira oculta, dentro da rede social.

As ditas adaptações ao modelo militarizado de escola, traduzidas em novas regras, vistas como intuito de educação apoiada na sensação de segurança e disciplina, possibilitam estar ocultando significados menos superficiais, como um projeto que visa a submissão dos indivíduos às estruturas sociais. $\mathrm{O}$ fetiche de que a segurança se apoia na reprodução da violência contra o outro, que na figura militar é visível pelo instrumento arma de fogo, pode tornar moroso o debate sobre segurança em outros espaços que não compartilham da militarização das escolas públicas. 


\section{CONSIDERAÇÕES FINAIS}

Após a pesquisa, as demandas iniciais puderam ser contempladas, verificando-se que a redução dos índices de violência apareceu como centro do processo de aceitação da GC. Também foi possível identificar os maiores medos dos sujeitos, mesmo que nunca tenham presenciado ou sofrido com o fenômeno, o que nos faz refletir sobre o sentimento dos indivíduos frente à vida urbana e o constante medo e resultados que a busca pela segurança podem gerar. O mal-estar construído sob o medo, como discutido, é um fenômeno de toda a sociedade e não apenas restrito à escola, porém suas manifestações e consequências são distintas, dependendo da instituição e dos mecanismos de combate.

O estudo em questão não teve e nem tem o objetivo de defender ou desqualificar o Projeto Piloto Escola de Gestão Compartilhada, mas entender as demandas da realidade na qual as escolas estão inseridas e como as problemáticas sociais podem e estão interferindo na reorganização escolar. É importante que a comunidade participe da construção e funcionamento de uma escola, porém também é necessário um amplo debate para que o trabalho seja desenvolvido da melhor maneira possível. É inegável a satisfação de muitos com a disciplina e sensação de segurança, porém, também há uma série de dúvidas e questões sobre a militarização ser o melhor caminho.

Perceber como a violência está influenciando a busca por intervenções nas escolas faz com que sejam necessárias ações que possibilitem proporcionar suporte da SEEDF quanto à questão segurança escolar, além de pensar medidas aplicáveis para as realidades das escolas públicas do DF, já que a maioria está desassistida. Considerando os dados obtidos e a possibilidade de conhecer um pouco a realidade de uma das escolas militarizadas no DF, surgem mais questionamentos do que certezas acerca das projeções e pesquisas sobre escolas públicas militarizadas, repercutindo a necessidade de aprimoramento do projeto já em aplicação, uma vez que é possível identificar muitas falhas, mas também resposta a alguns anseios da comunidade escolar.

O combate à violência escolar é um fenômeno complexo que demanda projeção de políticas educacionais que não secundarizem a diversidade, pois a exclusão de alunos justificada pela falta de enquadramento não apenas reproduz uma violência que passa a ser estruturada, como fere princípios de uma escola pública, retrocedendo na discussão dos valores de um espaço plural, popular e autônomo. Esses fatores são necessários para uma educação de qualidade dentro das exigências de um mundo globalizado que demanda pessoas com habilidades múltiplas, e não apenas capazes de reproduzir ordens e padrões. 
Independente de um projeto governamental, a educação precisa ser apreciada como um direito social, público e subjetivo que transpassa mandatos. As diretrizes educacionais devem estar alinhadas à formação cidadã. É perceptível a necessidade de maiores investimentos e projetos a serem aplicados nas instituições educacionais, porém, antes de tudo, a delimitação de quais objetivos estão sendo almejados é de extrema importância para caracterização da identidade de uma escola e de seu trabalho pedagógico.

A disciplina faz parte da aprendizagem, pois é ensinada por diversos atores e espaços. O tipo de disciplina que se almeja tem relação com a forma de pensar as regras e comportamentos no ambiente escolar, não somente como mecanismo de uniformização, mas como prática significativa e reflexiva. Um maior controle ditado por uma disciplina que visa a reprodução de comportamentos padronizados para minimizar conflitos pode gerar um sentimento de segurança, mas, em contrapartida, incita indivíduos não criativos ou dificulta o exercício democrático de decisões em um espaço construído para ensinar múltiplos pensamentos a emergirem na resolução de situações diversas.

Por fim, o que justifica reduzir os índices de violência nas escolas? Todas as medidas são válidas e aplicadas para todos os espaços, ou existe uma diferenciação no modelo educacional a depender da localidade, do público e da classe social? Quais parâmetros estão sendo utilizados para definir uma escola como de qualidade? O estudo sobre violência e sua manifestação nas instituições escolares pode oferecer reflexões sobre como pensar e construir os projetos escolares, assim como as novas diretrizes a serem aplicadas no contexto social em voga.

\section{REFERENNCIAS}

ABRAMOVAY, M. Violências nas Escolas. Programa de Prevenção à violência nas escolas. Brasília/DF: Flasco-Brasil, 2015, 21p. Disponível em: < http:/ / flacso. org.br/files/2015/08/Violencias-nas-Escolas.pdf > . Acesso em 11 set 2019.

BRASIL. Constituição da República Federativa do Brasil. Brasília, DF: Senado Federal, 1988.

BOURDIEU, P. O poder simbólico. 2. ed. Rio de Janeiro: Bertrand Brasil, 1998.

BRASIL. Lei $\mathrm{n}^{\circ}$ 9.394, de 20 de dezembro de 1996. Estabelece as diretrizes e bases da educação nacional. Brasília, DF, 1996. Disponível em: http://www. planalto.gov.br/ccivil_03/leis/19394.htm. Acesso em: 11 set. 2019. 
BRASIL. Decreto nº 9.665, de 2 de janeiro de 2019. Brasília, DF, 2019.

CAETANO, I.; VIEGAS, V. O Estado de exceção escolar: uma avaliação crítica das escolas públicas militarizadas. Aparecida de Goiânia: Escultura Produções Editoriais, 2016.

CALDEIRA, T. P. R. Cidade de muros: crime, segregação e cidadania em São Paulo. São Paulo: Editora 34/Edusp, 2000.

CARVALHO, J. F. Os sentidos da (in)disciplina: regras e métodos como práticas sociais. In: AQUINO, J. G. (org.). Indisciplina na escola: alternativas teóricas práticas. São Paulo: Summus, 1996.

DISTRITO FEDERAL. Lei no 4.751, de 07 de fevereiro de 2012. Brasília, DF, 2012. Disponível em: http://www.sinj.df.gov.br/sinj/Norma/70523/Lei_4751. html. Acesso em: 24 mar. 2020.

DISTRITO FEDERAL. Portaria Conjunta $\mathbf{n}^{\circ}$ 1, de 31 de janeiro de 2019. Brasília, DF, 2019. Disponível em: http://www.se.df.gov.br/wp-conteudo/ uploads/2019/02/portaria-conjunta-gestao-compartilhada_07fev19.pdf. Acesso em: 24 mar. 2020.

DAYRELL, J. A escola como espaço sócio-cultural. In: DAYRELL, J. (org.). Múltiplos olhares sobre educação e cultura. Belo Horizonte: UFMG, 1996.

DUNKER, C. I. L. A violência como nome para o mal-estar. In: Bala perdida: a violência policial no Brasil e os desafios para sua superação [S.l: s.n.], 2015.

FONSECA, C. Quando cada caso não é um caso: pesquisa etnográfica e educação. Revista Brasileira de Educação, n. 10, p. 58-78, jan./abr. 1999.

FOUCAULT, M. A Ordem do discurso: aula inaugural no Collège de France, pronunciada em 2 de dezembro de 1970. 15. ed. São Paulo: Loyola, 2007.

FOUCAULT, M. A Vigiar e punir: nascimento da prisão. Lisboa: Editora Edições 70, 2013. 
INSTITUTO DE PESQUISA ECONÔMICA APLICADA (IPEA). Atlas da Violência 2019. Brasília; Rio de Janeiro; São Paulo: Fórum Brasileiro de Segurança Pública, 2019. Disponível em:bhttp://ipea.gov.br/portal/images/ stories/PDFs/relatorio_institucional/190605_atlas_da_violencia_2019.pdf. Acesso em: 7 nov. 2019.

LAKATOS, E. M.; MARCONI, M. de A. Fundamentos de metodologia científica. 5. ed. São Paulo: Atlas, 2003.

NERI, M. Pesquisa percepções da crise. Rio de Janeiro: Fundação Getulio Vargas. Disponível em: https://www.cps.fgv.br/cps/bd/docs/Pesquisa_ Percepcoes-Da-Crise_MarceloNeri_FGVSocial.pdf. Acesso em: 5 nov. 2019.

WEBER, M. Ciência e política, duas vocações. São Paulo: Editora Cultrix, 1996.

ZIZEK, S. Violência: Seis reflexões laterais. São Paulo: Boitempo, 2014.

\begin{abstract}
Mariana Teixeira dos Santos
Pós-graduada em Ensino de Humanidades e Linguagens pelo Instituto Federal de Brasília (2020) - Campus Riacho Fundo; graduada em Ciências Sociais (2013) - bacharela em Sociologia e licenciada em Ciências Sociais - pela Universidade de Brasília (UnB). Professora da Secretaria de Estado de Educação do Distrito Federal (SEEDF). Atualmente, visa desenvolve trabalhos voltados para área de educação e análise de políticas públicas educacionais. E-mail: mariana.teixeira@ edu.se.df.gov.br

\section{Thiago de Faria e Silva}

Doutor (2016) e mestre em História Social (2011) pela Universidade de São Paulo (USP), onde também concluiu o bacharelado e a licenciatura em História (2007). Atualmente, desenvolve pesquisas sobre história e cultura da alimentação, linguagem audiovisual e ensino de História. É docente de História do Instituto Federal de Brasília (Campus Riacho Fundo) e, atualmente, coordena a PósGraduação em Ensino de Humanidades e Linguagens do IFB. E-mail: thiago. faria@ifb.edu.br
\end{abstract}

